\title{
Orienting to the policy sciences' sustainability problem
}

\author{
RICHARD L. WALLACE \\ Environmental Studies Program, Ursinus College, 601 E. Main Street, Collegeville, PA 19426, U.S.A.; \\ E-mail: rwallace@ursinus.edu
}

No one involved in an academic specialization likes to consider its mortality, especially when the questions being asked are incisive and stem from the concerns of a member of that discipline. In his essay "What future for the policy sciences?" Roger Pielke, a policy scientist in the environmental science program at the University of Colorado, raises a number of critical issues facing the policy sciences community. He believes that the policy sciences, as a distinct intellectual tradition, faces possible dissolution given the current number of individuals and institutions practicing its distinct approach to problem analysis. In defense of his thesis, Pielke describes a number of trends and conditions - both external and internal to the policy sciences community - that threaten policy sciences' sustainability, and he describes both potential and real effects of these trends on the policy sciences community.

While I agree with the essence of Pielke's challenge to the policy sciences community - that we need to consider and promote the sustainability of our intellectual traditions - I believe that he has undertaken only a partial problem orientation. He defines both the problem of sustainability and the goals for addressing it without providing the appropriate context. He proposes several hypotheses and substantiates his claims that the policy sciences community is currently unsustainable using a combination of personal experience and selected literature. However, in his arguments, he provides insufficient evidence that they substantiate the problem he claims. In essence, Pielke conducts a problem-orientation exercise but inadequately describes the problem and then presents insufficient trends and conditions to clarify the problem. This is unfortunate, because his goals and alternatives are critically important to the future of the policy sciences.

If the essays contained in this special section of Policy Sciences provide a fuller exposition of the problem, then the authors will have cooperatively provided a service to the policy sciences community. In this contribution, I will illustrate some of the issues that I believe bear on the description of the policy sciences' "sustainability problem," as well as trends, conditions, and perspectives that bear on the growth, existence, and sustainability of the policy sciences as an intellectual tradition.

A clarifying note on standpoint: Pielke and I come to the policy sciences from similar backgrounds and experiences. We are both policy scientists educated at institutions in the United States, where degrees steeped explicitly in policy sciences theory and methods are obtainable by working with second-generation policy scientists (i.e., those who studied under Harold Lasswell or Myres McDougal). We both hold academic positions in the field of environmental science and policy, and we both provide opportunities - in classes and otherwise - for our students to explore the 
policy sciences' methods of problem solving. Finally, and most importantly, we both firmly believe that the policy sciences should persist, and thus that this discussion of sustainability is one that must be undertaken by the wider policy sciences community.

\section{What is the context of the policy sciences sustainability debate?}

In his summary of factors that undermine policy sciences' sustainability, Pielke describes several external and internal pressures, all of which are important to the sustainability discussion. However, the relevance of each of these factors is mitigated by the context - the social and decision processes in which the sustainability debate takes place. Pielke fails to describe this context fully, thus leaving the reader to intuit the context from his arguments. Because of the incomplete nature of Pielke's problem orientation, his failure to provide accurate context promotes an imprecise understanding of the policy sciences' development in relation to the "militating factors" he believes threaten the policy sciences' sustainability.

The decision process of the policy sciences has a number of different referents, and the relation of these referents to each other and to the issue of sustainability is critical to establishing goals for (and to understanding the trends and conditions in relation to) sustainability of the policy sciences. These referents include the origins of the intellectual traditions of the policy sciences, the history of published work in the policy sciences, and the "institutionalization" of the policy sciences through various forums. Pielke does not identify these referents, or discuss their relation to each other or to the sustainability issue. It is this oversight that robs his arguments of their context. I believe that any discussion of sustainability must recognize these referents, and identify their relevance to the discussion. I will attempt to do so here.

\section{The development of the policy sciences intellectual community and scholarship}

In his criticisms of the policy sciences' sustainability, Pielke appears to address the policy sciences as a set of intellectual traditions, a field of study and practice, and a professional community. He does not acknowledge, however, that while the policy sciences are all of these things, the development of these three referents to the sustainability debate occurred at separate times and under the influence of separate (although related) decision processes. The confluence of intellectual tradition, field of practice, and professional community has now occurred, but in this discussion the three must first be considered separately in order to clarify how each influences the sustainability of the conflated whole.

The theories and methods we currently identify as the heart of the policy sciences began to take form in the early 20th century works of Harold Lasswell (and are compiled and expanded upon in Lasswell and McDougal, 1992; a comprehensive annotated bibliography of Lasswell's works is available in Muth et al., 1990). Lasswell was influenced by writings of John Dewey and other pragmatists in the first two decades of the 20th century. Lasswell's own writings before World War II set the stage for his more methodical elucidation of what we now call the policy sciences 
"frameworks," which took form during two decades of writings (e.g., Lasswell, 1951, 1956, 1960a, 1960b, 1970, 1971; Lasswell and Kaplan, 1950). This is not the appropriate forum for reviewing the intellectual history of the policy sciences. Suffice to state that they have a long and well-established history and tradition, as indicated at least by the publication history in the field.

Although Lasswell had been applying aspects of the policy sciences intellectual traditions in practice since his earliest published works, he and his colleagues began collaborating and publishing explicit policy sciences applications in the late 1940s with the establishment of the Policy Sciences Center at Yale University in 1948 and subsequent research and practice (e.g., Lasswell and Kaplan, 1950; Rogow and Lasswell, 1963; Arora and Lasswell, 1969; Dobyns et al., 1971). These works emerged during the same period in which Lasswell was adding both substance and clarity to the frameworks (reflected in the published works cited earlier). The study and practice of the policy sciences underwent significant growth following the creation of the journal Policy Sciences in 1970 and the matriculation of a cohort of Lasswell's students in the early 1970s. The work of these former students, in collaboration with Lasswell and each other, and on their own, represents the development of the second generation of policy scientists and an exponential growth in policy sciences research and practice (the individual works are too numerous to cite here, but are represented by, e.g., Brewer and deLeon, 1983; Reisman and Willard, 1988; Brunner and Ascher, 1992; Penna et al., 2004).

Following this growth in scholarship came additional research and practice by colleagues of the "second-generation" policy scientists, exploring formally the application of the works of Lasswell and his colleagues. While many of these subsequent policy scientists entered their careers at roughly the same time as Lasswell's former students, they came to the policy sciences somewhat later, and were responsible for yet another increase in policy sciences scholarship, beginning in the 1970s and continuing to the present (e.g., Burgess and Slonaker, 1978; Muth and Bolland, 1983; Willard and Norchi, 1993; Clark, 1997, 2002; Brown, 2002, 2003). Rodney Muth, whose response to Pielke's paper appears in this issue, is a member of this community. Most recently, a third generation of policy scientists has emerged. This is the community of young scholars - many (of those in academia) relatively recently tenured or still pre-tenure - to which Pielke, David Pelletier (author of another essay in this special section), and I belong. This community has grown to include more than a dozen young professionals whose published work in the policy sciences continues the intellectual tradition begun by Lasswell more than 80 years ago (e.g., Pielke et al., 2000; Cromley, 2002; Steelman, 2002; Auer 2003, 2004; Wallace, 2003; Wilshusen, 2003).

In addition to the scholarship cited earlier, members of all three aforementioned cohorts are involved in teaching activities that explicitly utilize the intellectual traditions of the policy sciences (the Policy Sciences Virtual Library at www.policysciences.org contains a number of representative course syllabi). At least 16 faculty at US institutions are now teaching policy sciences to students who are potential future policy sciences scholars and teachers. ${ }^{1}$ In the past 10 years, that number has increased by more than $30 \%$. While the significance of the overall population size can be debated, this rate of increase is notable. 


\section{The "institutionalization" of the policy sciences}

The growth of the policy sciences intellectual community since the 1970s has been marked by at least five substantive actions, all of which have served to "institutionalize" the policy sciences and clarify the professional community of which the aforementioned scholars and practitioners are a part. They are the establishment in 1982 of the Policy Sciences Annual Institute, the formation of the Society for the Policy Sciences in 1995, the convening of periodic policy sciences professional workshops beginning in 1997, the reconfiguration of the editorial board of Policy Sciences in 2002, and the first policy sciences distance learning seminar involving students and faculty from several institutions, which was conceived in 2003 and run in the spring of 2004.

The Policy Sciences Annual Institute has met at least annually since 1982 . Since the mid-1990s it has taken on the form of a small (60-125 attendees) professional meeting devoted to the shaping and sharing of values within the policy sciences community, the sharing of policy sciences scholarship and practice within the policy sciences community and with other interested individuals, and the forging of relationships between the policy sciences community and practitioners in other fields and in government agencies and non-governmental organizations. The goals of the institute are to promote the uses of the policy sciences for the identification, clarification, analysis and resolution of policy problems. Participants are invited to consider how the policy sciences have been and could be used to make authoritative decisions in the common interest. A connection between presenters' work and the intellectual traditions of the policy sciences is a requirement of participation (although exceptions do occur). The institute takes place during 4 days each October, with 3 days of formal sessions. As with many other professional meetings, the agenda for the institute fills quickly after the initial request for proposals is distributed in the spring of each year. Overall, the institute is a professional meeting devoted to the dissemination of scholarship and practice in the policy sciences, and has grown in both its formality and attendance as it has matured. ${ }^{2}$

The Society for the Policy Sciences was established in 1995 in part as a response to earlier discussions of the sustainability issue within the policy sciences community. The Society's charter members recognized many of the sustainability-related concerns that Pielke raises: the need to differentiate the policy sciences from problem-blind, acontextual, methodologically constrained, or otherwise partial approaches; to systematically update and advance the "intellectual capital" of the policy sciences; and to actively attract and train aspiring policy scientists to replace retiring policy scientists (from the Society's "working papers" at www.policysciences.org).

The formation of the Society was followed by the rapid growth in the number of aspiring policy scientists to enter academic positions - the 30\% growth in policy scientists teaching policy science courses referred to earlier. While not necessarily cause and effect, the creation of the Society was instrumental in this growth because it substantiated a community that had existed to that point without a central unifying community structure. The creation of the Society - combined with the formal relationship established between the Society and the journal - provided validation for professionals interested in pursuing policy sciences as a field of scholarship. In 
its wake, the number of policy scientists publishing in peer-reviewed journals has also increased significantly (as described earlier). The society has enjoyed active participation in governance from representatives of all the professional policy sciences cohorts. $^{3}$

The existence of the Society also led to the establishment of a series of periodic workshops, the purposes of which are to bring together policy scientists - current and aspiring, Society members and not - to explore issues of mutual interest. The three workshops that have occurred since 1997 have been attended by a broad representation of the various policy sciences professional cohorts, addressed issues concerning the explicit use and understanding of the work of Harold Lasswell, served to advance the understanding of policy sciences' intellectual capital, and fostered the sense of community that is one of the attributes most desired among the Society's membership.

Although there have been no workshops since 2002, in 2003 and 2004 Society members established a new precedent in Society-sponsored professional productivity, creating and running a distance-learning course entitled The World Revolution of Our Time. The course was designed as a prototype, to explore the viability of exercises in community-building and knowledge diffusion in the policy sciences using distancelearning technology and the Internet. The course was based on Lasswell's works, and involved a cross section of Society members, plus more than 30 students at three schools across the United States. The seminar has provided a model for future courses in which the dual goals of community-building and the shaping and sharing of knowledge and skills can take place to benefit a large and diverse group of interested individuals.

The reconfiguration of the editorial board of the journal Policy Sciences in 2002 was also a notable promotion of the intellectual traditions, as the new board included members of all policy scientist cohorts. This reformation of the board marked the first opportunity for third-generation policy scientists to participate in fashioning the direction of the journal, and coincided with the journal becoming an official publication of the Society.

Since the early 1980s, and particularly during the past decade, the policy sciences community has become increasing institutionalized in ways that explicitly promote the goals of community-building and professional advancement. The increasing formality with which policy scientists interact has lent credence to the community, which can be gauged by factors such as policy sciences-explicit publications, explicit policy sciences courses, junior faculty involvement in Society governance, the quality and quantity of attendance at the annual institutes, and a number of other criteria that are relevant to the discussion of sustainability.

\section{Why is the glass half full, and not half empty?}

Pielke's problem statement makes several assumptions about the state of the policy sciences community in relation to the factors he describes as impeding sustainability. While he does not provide a concise statement of the problem, he describes a series of related concerns and implies that the several internal and external factors conspire to undermine sustainability. Because he fails to provide sufficient delineation of the trends and conditions in the growth and development of the policy sciences, the direct 
connections he implies between his influencing factors and sustainability are unclear - they sound logical, but he is grasping at causality. In turn, this lack of clarity reduces many of his arguments to well-educated conjecture, which convey a sense that Pielke's arguments are unjustifiably negative - in effect, a "glass half empty" view of the policy sciences. To explore this, I will briefly review Pielke's influencing factors in relation to the trends and conditions presented earlier.

\section{The danger of generalizing influences}

The external factors that Pielke describes are without doubt serious concerns to problem oriented, applied researchers and practitioners. His descriptions of the reverence for prediction, the axiology of science, and the politicization of research all ring true in the context of the debate between applied, problem-oriented approaches to policy problem solving and the partial, positivistic, and often subjective approaches that dominate the debate. However, that does not make them impediments to the development of the policy sciences community. Pielke overstates the potential effect of these factors by likening their influence on the theoretical constructs of applied, problemoriented practice to their influence on individuals forging applied, problem-oriented careers steeped in the policy sciences' intellectual traditions. Although the two are related, they are not the same. This is illustrated by the trends in the internal factors that Pielke cites, which are similarly less pessimistic than Pielke would have us believe.

In academia, policy sciences practitioners of all cohorts have successfully received advanced degrees, found gainful employment at reputable institutions, published and taught in the policy sciences, and received tenure, despite the societal reverence for prediction, the dominant axiology, or the politicization of science. As well, considering each of Pielke's internal factors in relation to the trends documented earlier, I believe that the community is experiencing acceptable growth to sustain itself. My differing appraisal of the social process that Pielke describes is based on my observation of and involvement in both the policy sciences community and other, similar scholarly groups that have faced, and withstood, the same challenges that Pielke claims are threatening the policy sciences.

\section{The challenges faced by innovative intellectual traditions}

The policy sciences community bears some resemblance to other intellectual communities that respond to partial problem-solving approaches with innovation. The "fields" of environmental studies, ecological economics, and conservation biology are three intellectual traditions that have been built on the desires to foster community from problem oriented concern (Soulé, 1985, 1986; Costanza, 1991; Costanza et al., 1997; Maniates and Whissel, 2000). Since their respective inceptions, all have overcome Pielke's external and internal obstacles to flourish as metadisciplines that successfully bridge partial responses to environmental problems. In each case, the members of the community in its earliest stages battled with the positivistic biases of the majority of their colleagues, forging bonds through the establishment of institutions (e.g., 
professional societies, annual meetings, scholarly journals) and slowly creating an infrastructure within which each field now comfortably rests. ${ }^{4}$

These fields still face the same challenges - perhaps it is unavoidable that innovators desiring to change well-established intellectual traditions face long-term resistance. The field of environmental studies began to develop in the late 1960s; conservation biology and ecological economics grew out of their more traditional parent disciplines in the 1980s. All three are subject to the same disciplinary biases now as when they were established, but the salient point in recognizing their ability to develop is that these biases - e.g., Pielke's internal and external factors - are too diffuse to halt the progress of individuals dedicated to forging careers as innovators. As importantly, broad influencing factors such as those Pielke raises are not so all-encompassing that they conspire to limit the freedom of these individuals to pursue innovative career choices in professional institutions. If they did, these fields would not have become so well and easily established, and we would not be reaping the intellectual and applied benefits of their robust communities. In essence, Pielke's concerns are academic - they are real, and for some individuals they may have the effects about which Pielke warns, but the assumption that they will conspire to deny the policy sciences sustainability is premature.

\section{Conclusions: The "alternative future" is now}

Despite the validity of Pielke's concerns, he does a poor job of placing them in the context of the growing intellectual tradition of the policy sciences and he fails to recognize the degree to which his "alternative futures" are already occurring in the policy sciences community - specifically the clarifying of policy scientists' unique perspectives and the institutionalization of the policy sciences community and intellectual traditions.

How active a community of scholars and practitioners is in clarifying their perspectives depends on the criteria used to evaluate their activity. Pielke does not offer criteria for projecting the success of this "alternative future," but I find the trends encouraging on the basis of several criteria, including recent publications in Policy Sciences and other journals and books by members of the Society, the quality of the papers and panel sessions presented in recent years at the annual institute, the nature of the policy sciences-explicit courses being offered by members of the Society, and the existence of explicit policy sciences content in the work of junior scholars who are receiving tenure at reputable colleges and universities.

The institutionalization that each new, innovative discipline must undergo is a process that relies on the confluence of many factors, most significantly a critical mass of dedicated individuals. In the policy sciences community, there was a substantial lag in reaching this critical mass (during which time second-generation policy scientists were busy publishing, but not institutionalizing their community), and so the growth of policy sciences institutions took an exponential upward turn only in the past decade or so, with the establishment of the Society and the subsequent changes to the structure and function of the annual institute and editorial board of the journal. In other words, while our intellectual tradition has a long and rich history, our institutions are quite young. 
So where is the problem? More than at any time in the history of our intellectual tradition, we have larger numbers of young policy scientists publishing explicit work, teaching explicit courses, receiving tenure, and being active in our institutions. Our overall numbers are still small, but the trends seem cause for optimism, not alarm. My fear is that Pielke's essay will be considered another work in the list of critics of the policy sciences, and that because of his selective choice and presentation of trends and conditions that he might inadvertently provide fodder for criticism in a way that is misrepresentative of the policy sciences community.

Of course, time will be the ultimate arbiter, and my projections on the basis of observable trends and comparative institutions may be reason for optimism, but they are not without responsibility. In their contributions to this discussion, David Pelletier and Rod Muth pose a number of specific alternatives to fostering the intellectual traditions of the policy sciences. Their ideas should be considered as strategies for the maximization of shared values - the augmentation of the policy sciences community and its institutions, and the individual rewards we can reap through our involvement in both. As members of this community we must take seriously the challenges to sustainability by clearly delineating our individual and institutional goals, placing ourselves accurately in the context of the intellectual traditions, and acting in a way that promotes the growth of the community - the process we have ably begun and, I hope, will continue to foster.

\section{Notes}

1. Fourteen of the 16 teach graduate students; the other two teach in purely undergraduate colleges.

2. All observations about the institute are based on personal experience. I have attended the institute annually since 1993 and co-chaired the institute in 2003 and 2004.

3. Again, all observations are based on personal observation; I am a founding member of the Society and currently a member of its executive council.

4. For more insight into the formalization of conservation biology and ecological economics, see their respective journals and web sites: Conservation Biology and www.conbio.org and Ecological Economics and www.ecoeco.org or www.ussee.org. Environmental studies, being a field comprised largely of iconoclasts (this author included), has avoided institutionalization and so never established a principal journal or society. For a discussion of the development of the field of environmental studies, see Maniates and Whissel (2000).

\section{References}

Arora, S. K. and H. D. Lasswell (1969). Political Communication: The Public Language of Political Elites in India and the United States. New York: Holt, Rinehart and Winston.

Auer, M. R. (2004). Restoring Cursed Earth: Appraising Environmental Policy Reforms in Central and Eastern Europe and Russia. Boulder: Rowman \& Littlefield.

Auer, M. R. (2003). 'Reflections on the craft of advising: Expert advice and U.S. foreign aid policy-making,' International Studies Perspectives 4: 211-227.

Brewer, G. D. and P. deLeon (1983). The Foundations of Policy Analysis. Homewood, IL: Dorsey Press.

Brunner, R. D. and W. Ascher (1992). 'Science and social responsibility,' Policy Sciences 25: 295-331.

Brown, S. R. (2002). 'Structural and functional information,' Policy Sciences 35: 285-304.

Brown, S. R. (2003). 'Conscience, institutions, and knowledge,' Policy Sciences 36: 46-53.

Burgess, P. M. and L. L. Slonaker (1983). The Decision Seminar: A Strategy for Problem-Solving. Columbus: The Mershon Center of Ohio State University. 
Clark, T. W. (1997). Averting Extinction:Rreconstructing Endangered Species Policy. New Haven, CT: Yale University Press.

Clark, T. W. (2002). The Policy Process: A Practical Guide for Natural Resource Professionals. New Haven, CT: Yale University Press.

Costanza, R., ed. (1991). Ecological Economics: The Science and Management of Sustainability. New York: Columbia University Press.

Costanza, R., J. H. Cumberland, H. E. Daly, R. Goodland and R. B. Norgaard (1997). An Introduction to Ecological Economics. St. Lucie, FL: St. Lucie Press.

Cromley, C. M. (2002). 'Bison management in Greater Yellowstone,' in R. D. Brunner, C. H. Colburn, C. M. Cromley, R. A. Klein and E. A. Olson, eds., Finding Common Ground: Governance and Natural Resources in the American West. New Haven, CT: Yale University Press, pp. 126-158.

Dobyns, H. F., P. L. Doughty and H. D. Lasswell, eds. (1971). Peasants, Power, and Applied Social Change: Vicos as a Model. Beverly Hills, CA: Sage Publications.

Lasswell, H. D. (1951). 'The policy orientation,' in D. Lerner and H. D. Lasswell, eds., The Policy Sciences: Recent Developments in Scope and Method. Stanford, CA: Stanford University Press, pp: 3-15.

Lasswell, H. D. (1956). The Decision Process: Seven Categories of Functional Analysis. College Park: Bureau of Governmental Research and College of Business and Public Administration, University of Maryland.

Lasswell, H. D. (1960a). Psychopathology and Politics. New York: Viking Press.

Lasswell, H. D. (1960b). 'Technique of decision seminar,' Midwest Journal of Political Science 4: 213-236.

Lasswell, H. D. (1970). 'The emerging conception of the policy sciences,' Policy Sciences 1: 3-14.

Lasswell, H. D. (1971). A Pre-view of Policy Sciences. New York: American Elsevier.

Lasswell, H. D. and A. Kaplan (1950). Power and Society. New Haven, CT: Yale University Press.

Maniates, M. F. and J. C. Whissel (2000). 'Environmental studies: The sky is not falling,' BioScience 50: 509-517.

McDougal, M. S., H. D. Lasswell and L. Chen (1980). Human Rights and World Public Order. New Haven, CT: Yale University Press.

Muth, R. and J. Bolland (1983). 'Social context: A key to effective problem solving,' Planning and Changing 14: $214-225$

Muth, R., M. F. Finley and M. F. Muth (1990). Harold D. Lasswell: An Annotated Bibliography. New Haven, CT: New Haven Press.

Penna, F. J., M. Thormann and J. M. Finger (2004). 'The Africa music project,' in J. M. Finger and P. Shuler, eds., Poor People's Knowledge: Promoting Intellectual Property in Developing Countries. Oxford: Oxford University Press.

Pielke, Jr., R. A., D. Sarewitz and R. Byerly, Jr. (2000). 'Decision making and the future of nature: Understanding and using predictions,' in D. Sarewitz, R. A. Pielke, Jr. and R. Byerly, Jr., eds., Prediction: Science, Decision Making, and the Future of Nature. Covelo, CA: Island Press, pp: 361-388.

Reisman, W. M. and A. R. Willard (1988). International Incidents: The Law that Counts in World Politics. Princeton, NJ: Princeton University Press.

Rogow, A. A. and H. D. Lasswell (1963). Power, Corruption, and Rectitude. Englewood Cliffs, NJ: PrenticeHall.

Soulé, M. E. (1985). 'What is conservation biology?’ Bioscience 35: 727-734.

Soulé, M. E., ed. (1986). Conservation Biology: The Science of Scarcity and Diversity. Sunderland, MA: Sinauer Associates.

Steelman, T. A. (2002). 'Community-based involvement in biodiversity protection in the United States,' in T. O'Riordan and S. Stoll-Kleemann, eds., Biodiversity, Sustainability, and Human Communities: Protecting Beyond the Protected. Cambridge: Cambridge University Press, pp. 142-167.

Wallace, R. L. (2003). 'Social influences on conservation: Lessons from U.S. recovery programs for marine mammals,' Conservation Biology 17: 104-115.

Willard, A. R. and C. H. Norchi (1993). 'The decision seminar as an instrument of power and enlightenment,' Political Psychology 14: 575-606.

Wilshusen, P. R. (2003). 'Exploring the political contours of conservation: A conceptual view of power in practice,' in S. R. Brechin, P. R. Wilshusen, C. L. Fortwanger and P. C. West, eds., Contested Nature: Promoting International Biodiversity with Social Justice in the Twenty-First Century. Albany: State University of New York Press, pp. 41-58. 